\title{
Educación sexual y afectiva en libros de texto de Ciencias Sociales y Ciencias Naturales de Primaria en el sistema educativo de Castilla La Mancha
}

\author{
María Teresa Bejarano Franco ${ }^{1}$
}

\begin{abstract}
RESUMEN
El artículo presenta la actividad investigadora sobre revisión de imágenes con perspectiva de género en libros de texto de primaria utilizados en Castilla La Mancha. El objetivo de esta tarea se centra en saber si se está impartiendo el modelo de educación sexual y si se transmiten conocimientos sobre lo afectivo sexual. Para ello, se escogieron dos áreas de conocimiento, Ciencias Sociales y Ciencias Naturales y se seleccionaron 90 imágenes. Se aplicó un instrumento de recogida de datos denominado tabla de análisis diseñada a partir del planteamiento sobre educación en sexualidad que expone la OMS (2006).El análisis se llevó a cabo utilizando la técnica de análisis de contenido (Hsieh y Shannon, 2005). Las conclusiones revelan que no se trabaja el modelo de educación en sexualidad y que aún se siguen mostrando contenidos sesgados sobre lo afectivo-sexual.
\end{abstract}

PALABRAS CLAVES: Educación sexual. Educación afectivo-sexual. Libros de texto. Etapa de primaria.

Sexual and affective education in textbooks of Social Sciences and Primary Sciences in the educational system of Castilla La Mancha

\begin{abstract}
The article presents the research activity on the revision of images with a gender perspective of primary textbooks used in Castilla La Mancha. The
\end{abstract}

\footnotetext{
${ }^{1}$ Doctora en Ciencias de la Educación. Universidad de Castilla La Mancha, Facultad de Educación de Ciudad Real, España.mariateresa.bejarano@uclm.es.
} 
objective of this task is to know if the sexual education model is being taught and if knowledge about sexual affectivity is transmitted. For this, two areas of knowledge were chosen: Social Sciences and Natural Sciences and 90 images were selected. The analysis was carried out using the content analysis technique (Hsieh and Shannon, 2005) applying a data collection instrument called the analysis table designed based on the approach on sexuality education presented by the OMS (2006). The data analysis has been carried out under the mixed paradigm. The conclusions reveal that the model of sexuality education is not being worked on and that there are still biased contents about the affectivesexual.

KEYWORDS: Sex education. Affective-sexual education. Textbooks. Primary stage.

\section{Introducción}

Este artículo aporta una visión aproximada y contrastada sobre la enseñanza de la educación en sexualidad ligada a los afectos (educación afectivo-sexual) en los libros de textos de Ciencias Sociales y Ciencias Naturales en la etapa obligatoria, denominada primara, en España. Para ello, se ha tomado de referencia teórica el modelo centrado en el concepto de sexualidad promocionado por la Organización Mundial de la Salud (2006).

La sexualidad es un aspecto central del ser humano presente a lo largo de su vida. Abarca al sexo, las identidades y los papeles de género, el erotismo, el placer, la intimidad, la reproducción y la orientación sexual. Se vivencia y se expresa a través de pensamientos, fantasías, deseos, creencias, actitudes, valores, conductas, prácticas, papeles y relaciones interpersonales. La sexualidad está influida por la interacción de factores biológicos, psicológicos, sociales, económicos, políticos, culturales, éticos, legales, históricos, religiosos y espirituales. (OMS, 2006). 
El abordaje de la sexualidad en las aulas está respaldado por los derechos humanos y varias organizaciones internacionales como UNESCO 2014. La enseñanza de ésta tiene que ser un derecho garantizado por todas las sociedades. La sexualidad es un tema educable y permite desarrollar parte del potencial humano en la niñez y juventud y contribuye a la construcción de una educación integral (ONUSIDA, 2005).

Diversos compromisos internacionales, como los "objetivos de Desarrollo de Milenio" que la ONU estableció en 2013 y la estrategia de "Llegar a cero" de ONUSIDA en 2010, integran la Educación en sexualidad y la igualdad de género como retos a escala mundial para garantizar el acceso equitativo a la educación, a la salud y a la calidad de vida.

Encontramos otros organismos internacionales, como la UNESCO, que elaboran documentos como Orientaciones Técnicas Internacionales sobre Educación en Sexualidad (2010) centrados en argumentos que justifican la educación en sexualidad que responde a una necesidad tanto nacional como internacional:

En la actualidad, son muy pocas las personas jóvenes que reciben una adecuada preparación para la vida sexual. Este hecho los hace potencialmente vulnerables frente a la coerción, el abuso, la explotación, el embarazo no planificado y las infecciones de transmisión sexual (ITS), incluyendo el VIH. (UNESCO, 2010, p. iii)

Este documento ofrece sólidas recomendaciones técnicas sobre las características que todo programa educativo efectivo debe tener en base a la enseñanza de la sexualidad.

Cabe destacar que es de especial relevancia que prevalezca en el sistema educativo público básico una educación en sexualidad con perspectiva de género para así hacer frente al sexismo, a la violencia de género y al desarrollo integral de la persona. 
Además, el desarrollo de la sexualidad de manera integral ayuda a reforzar la autoestima, la autoimagen, a sentirnos con más vitalidad y a pensar en la importancia de una vida sexual adecuada para el bienestar y la salud física y psíquica de los individuos. Por lo tanto, la faceta sexual debe estar integrada en la personalidad del individuo ya que le confiere unos valores netamente humanos y, por ello, debe ser parte del currículo escolar (BEJARANO \& MATEOS, 2014).

Entonces, es necesaria una buena base educativa y pluridimensional de esta educación para prevenir y abordar las desigualdades de género. Aquí entra en juego una educación que debe atender a lo afectivo y a lo sexual. Ello se complementa con el cuidado, la formación de las personas sexuales, sexuadas y eróticas, con nuestros modos y peculiaridades de ser y estar en un mundo global a la hora de vivir de nuestros cuerpos, nuestros afectos y sentimientos hacia uno mismo y hacia los demás. Por ello, las instituciones educativas, entre ellas los colegios, deben dar respuestas a las demandas de la población escolar desde el currículo y enseñar competencias que interfieran en la diversidad sexual, en las emociones y las redes afectivo sexuales, como forma de entender al otro/a, de respetarlo/a (BEJARANO \& MATEOS, 2016).

\section{Revisión de modelos sobre sexualidad en educación}

Ya Weeks (1999) nos invitaba a reflexionar sobre cuestiones como la posición del sexo en nuestras vidas, la identidad y el placer o la responsabilidad. Basándose en esto, dicho autor distingue tres posiciones sobre la moral sexual: la absolutista, donde el sexo se ve como algo alborotador y peligroso, tomándolo como un tema tabú y con restricciones, la libertaria, totalmente contraria a la absolutista al concebir el sexo como algo benévolo, algo primario, adoptando unos valores que llegan a ser radicales, y, por último, la liberal, un punto intermedio entre las anteriores. 
Por otro lado, Morgade, Baez, Zattara y Díaz Villa (2011) hacen una distinción más concreta de modelos sobre la sexualidad en educación:

- Modelo biologista: reduce la sexualidad a aspectos biológicos, tales como la anatomía y el aparato reproductor, de una forma totalmente teórica.

- Modelo biomédico: trata sobre las consecuencias negativas del mal uso de la sexualidad, tales como el VIH y Sida o embarazo.

- Modelo moralizante: aborda las cuestiones del plano ético que apoyan las expresiones de la sexualidad. Destaca la genitalidad como el centro de la sexualidad, instruyendo la abstinencia sexual como modo de control.

- Modelo de la sexología: valora las prácticas sexuales, desmiente las creencias y explora maneras de conocer del cuerpo sexuado. En dicho modelo, la sexualidad es entendida como dimensión de la construcción de la subjetividad que se da durante toda la vida.

- Modelo normativo o judicial: aborda temas desde un punto de vista normativo, teniendo en cuenta los Derechos Humanos, como el acoso o la violencia.

\section{Importancia del análisis de materiales curriculares}

La actual Ley Educativa (LOMCE, 2013) apuesta por la coeducación, por lo que los materiales didácticos empleados en las aulas y en particular los libros de texto deben seguir una línea coeducativa. Como muestran Martínez Bonafé y Rodríguez Rodríguez (2010) los libros de texto son el recurso didáctico dominante a la hora de desarrollar los contenidos en las aulas. Diz y Fernández Rial, (2015), sostienen que los libros de texto son difusores de ideologías y modelos sociales sobre los temas que abordan. A estos libros de texto también se les debe incorporar la modalidad del lenguaje icónico, siendo un complemento educativo fundamental para manifestar las cuestiones de igualdad (BEJARANO \& MATEOS, 2014). 
Lomas (2007) nos avisa de que los libros de texto reflejan una realidad a partir de los estereotipos y prejuicios, entre ellos, actitudes sobre la mujer y el hombre y que, al ser el recurso didáctico dominante, no permite desarrollar experiencias interdisciplinares o globalizadoras ni otras estrategias y metodologías. La consecuencia de esto es el que el alumnado no desarrolla la capacidad de análisis-crítica, y por tanto interiorizan lo que ven en los libros sin cuestionárselo.

Como dice Blanco (2007):

Cuando utilizamos un libro de texto y otro material, no estamos simplemente enseñando (y aprendiendo) Matemáticas, Historia, Lengua o Música; estamos enseñando (y aprendiendo) cómo es el mundo, cómo ha llegado a ser así, quién ha contribuido a ello y de qué manera, qué vale la pena y que es insignificante... Y también enseñamos (y aprendemos) quiénes somos nosotros y nosotras, qué se espera que hagamos, qué es posible y qué es apropiado, qué expectativas es razonable tener, a quién podemos tomar como modelo, dónde está nuestra genealogía... Esto es así porque -la mayoría de los libros escolares- reflejan y trasmiten los modelos dominantes contribuyendo a reproducir sesgos, estereotipos y prejuicios sexistas, clasicistas y racistas (p.108).

Por esto, hay que apostar por analizar los libros que se utilizan y conseguir nuevos modelos que muestren otra perspectiva sobre el mundo y potencien la igualdad. Blanco (2007) afirma que la importancia de analizar los libros radica en poder identificar los materiales sexistas y transformarlos para potenciar una educación que genere libertad en ambos sexos.

Pérez López (2011) advierte que el sexismo aparece en los libros de texto de dos formas distintas: explicita, cuando existe preferencia de un sexo sobre otro, o latente, si aparecen perspectivas estereotipadas, como actitudes y comportamientos. Asimismo, otros autores como Terrón y Cobano (2009) 
afirman que tanto el lenguaje icónico como el verbal que aparece en las imágenes son elementos cruciales para propiciar una correcta coeducación.

Como conclusión, debemos apostar por una coeducación en la transmisión de conocimiento tanto a nivel visual como textual, teniendo en cuenta que "coeducar consiste en enseñar y aprender a vivir la vida en libertad física y mental, en vivir sin miedos, en hablar de sueños, en pelear por la justicia" (CARRERAS, SUBIRATS \& TOMÉ, 2012, p. 53) y que, para lograr esto, es necesario saber analizar los recursos utilizados para ver si cumplen con los principios coeducativos.

\section{Planteamiento metodológico}

La investigación recogida en este artículo se plantea desde un enfoque mixto ya que, como afirman Hernández-Sampieri, Fernández Collado, y Baptista (2014), incluye métodos usados para representar un conjunto de

procesos sistemáticos, empíricos y críticos e implican la recogida de datos tanto cualitativos como cuantitativos y su posterior análisis con la finalidad de estudiar y comprender el objeto de estudio, en este caso, cómo se representa el modelo de educación en sexualidad y afectividad con perspectiva de género en las imágenes de los libros de texto de Ciencias Sociales y Naturales de la etapa de educación primaria.

También es concebida como una investigación innovadora porque, a partir de incluye un modelo coeducador que mejora las prácticas educativas relacionadas con la Educación en sexualidad e igualdad, produciendo una reflexión en las personas involucradas en la educación. Para innovar es necesario la trasformación de las prácticas de aquellas personas que tienen un papel importante en el proceso de enseñanza-aprendizaje, principalmente profesores/as y alumnos/as, además de replantear la dinámica y estructura de aquellos procesos y escenarios educativos que están vinculados a dicha innovación (DÍAZ BARRIGA-ARCEO, 2010). 


\section{Técnica e instrumento}

Se ha elegido la técnica basada en el análisis de contenido, una técnica que facilita el estudio de la transmisión de significados de textos escritos y/o imágenes gracias a una interpretación apoyada en una serie de categorías e indicadores preestablecidos (HSIEH \& SHANNON, 2005). Asimismo, según indica Bisquerra (2014) esta técnica es una actividad que tiene un carácter planificado y sistemático con la finalidad de recogida de información a través de la revisión de documentos escritos o imágenes pertenecientes, en este caso concreto, a los libros de texto analizados. Para ello, se ha empleado como instrumento de recogida de datos una tabla de análisis2 diseñada a partir de las cinco dimensiones que se muestran a continuación, cada dimensión quedad definida a modo de criterios que se van a ir identificando en cada imagen escogida:

1. Igualdad: compuesta por varios criterios, tales como la presencia/no presencia de mujeres, hombres u otros, el tamaño de la imagen, protagonismo y roles sexuados.

2. Educar en salud: se hace referencia a los estilos de vida (alimentación, actividad física, relación con el entorno, etc.) y la sexualidad ligada a la salud corporal, diferenciando siempre el sexo que lo ejerce.

3. Relaciones afectivo-sexuales: ligada a la trasmisión de emociones, las interacciones humanas tales como: las actitudes de cariño, el abuso o violencia sexual y las fobias sexuales. Se tiene en cuenta la definición de sexualidad referenciada por la OMS (2006).

4. Cuerpo/Cambios corporales: se recogen aspectos ligados a los aspectos físicos, haciendo hincapié en los estereotipados, y a la representación de cambios corporales.

5. Diversidad familiar: en dicha categoría hay que indicar si se manifiesta la diversidad familiar en las distintas imágenes analizadas. 
Por tanto, la tabla cuenta con cinco dimensiones, cada una de estas está formada por criterios, que servirán de claves identificativas a la hora de analizar la imagen. Además de dichas dimensiones, también la tabla tiene habilitado un espacio para hacer referencia al texto y al pie de la imagen, e indicar si el lenguaje es o no inclusivo y si se corresponde con lo que sucede en la imagen. Asimismo, existe otro espacio que es utilizado para señalar la presencia de las mujeres y de hombres en todas las imágenes del libro analizado.

\section{Muestra del estudio}

Indicamos que las imágenes escogidas en los libros de texto, constituyen la muestra del estudio. El criterio general para seleccionar los libros fue que estuviesen en vigor actualmente en la Comunidad Autónoma de Castilla la Mancha (España). La muestra está constituida por un total de 90 imágenes, recogidas en seis libros de texto de la editorial Savia-SM de las asignaturas: Ciencias Sociales y Ciencias Naturales de los niveles de $2^{\circ}, 4^{\circ}$ y $6^{\circ}$ de Educación Primaria. Estas imágenes constituyen la muestra aleatoria, al ser seleccionadas al azar dentro los libros escogidos. De acuerdo con Hernández Sampieri, Fernández Collado y Baptista (2014), esta muestra es aquella en la que todos los elementos que pertenezcan al campo donde se inscribe la investigación, tienen la misma posibilidad de ser escogidos a través de una selección totalmente aleatoria.

\section{Análisis de datos y resultados}

El análisis de datos está dividido en cada una de las dimensiones y apartados de los que está compuesta la tabla utilizada para dicho fin. A su vez, cada dimensión abarca por separado los datos analizados según los libros de texto. Los datos han sido trasladados a una hoja excel que recoge toda la información de la que consta la tabla de análisis. El análisis se ha 
realizado imagen por imagen. A continuación se muestran los datos en base a la dimensión Relaciones afectivo-sexual en libros de texto de Ciencias Sociales y Ciencias Naturales.

En la revisión de las imágenes de los libros de Ciencias Naturales del $2^{\circ}$ curso de educación primaria, aparece solamente la trasmisión de las emociones que se expresan en los personajes femeninos y masculinos. Estas emociones quedan recogidas en la gráfica, 1. La emoción más expresada en mujeres es la alegría, siendo la más expresada por los hombres la dulzura. Aparecen otras manifestadas como el asombro y sorpresa en mujeres y el miedo en hombres. En este libro se detecta como las mujeres son las portadoras de las emociones respecto a los hombres ya que mayoritariamente ellas son las que representan más expresiones emotivas.

\section{GRÁFICA 1. Emociones}

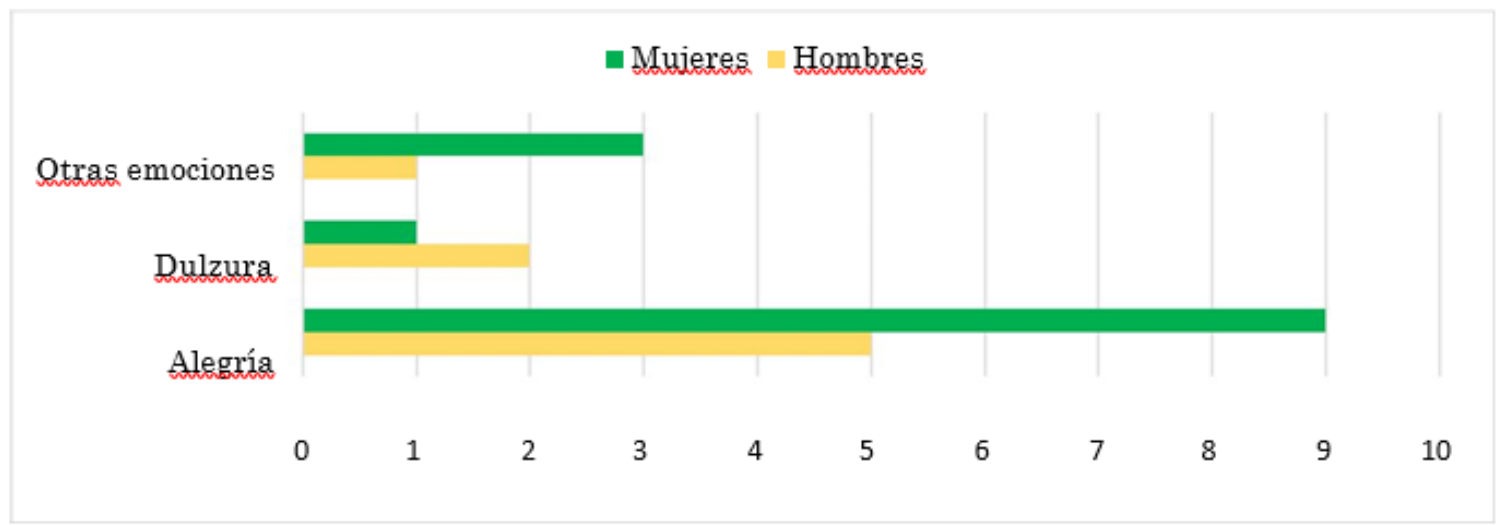

Fuente: Propia, 2017

En lo que tiene que ver con las interacciones humanas encontramos, como bien nos señala la figura 1, que en un elevado número de las imágenes analizadas, aparecen ambos sexos relacionándose. Un total del $47 \%$ de las ocasiones.

Por otro lado, se han revisado las actitudes de relación mutua en la que haya manifestación de cariño como un indicador relacionado con esta dimensión. En análisis revela, que en el $47 \%$ de las imágenes mujeres y hombres no expresan relación alguna. Un 18\% de las imágenes representan a mujeres y hombres en una misma imagen pero sin expresar relación 
alguna entre ellos. En un $15 \%$ de las imágenes aparecen hombres solos sin relación. Y el 20\% de las imágenes si representa mujeres y hombres en posición de interacción mostrándose en posición de bienestar mutuo.

FIGURA 1. Interacciones humanas

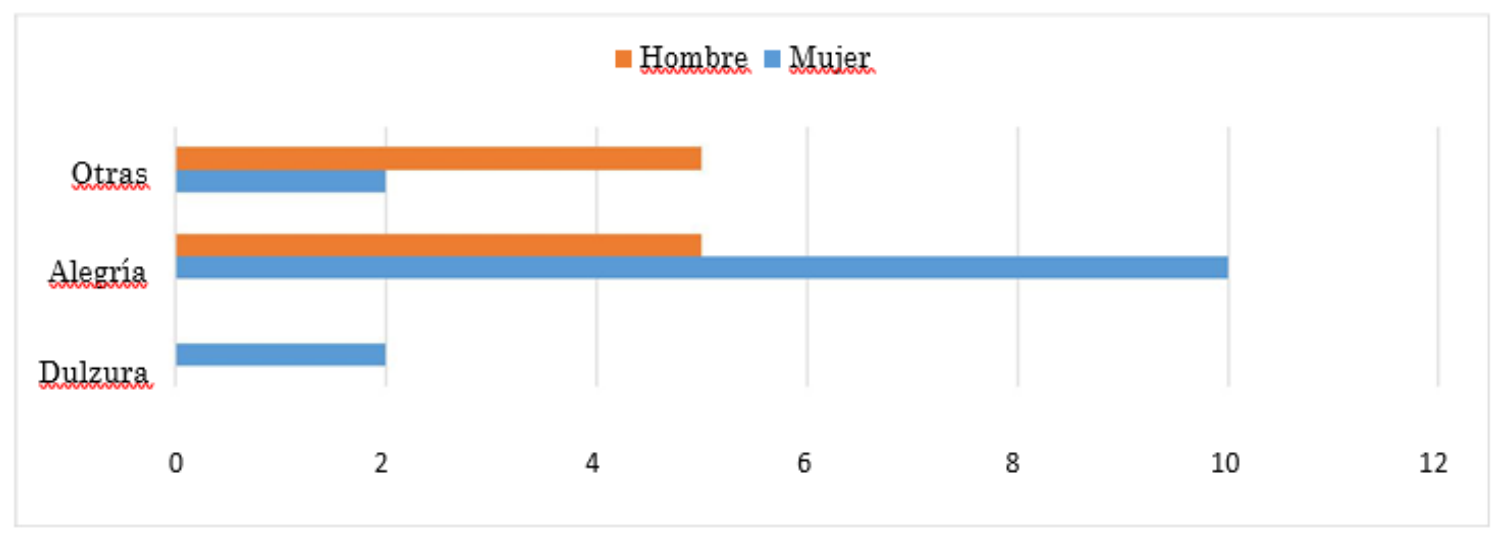

Fuente: Propia, 2017

Por otra parte, de la otra categoría de esta dimensión que está relacionada con las interacciones humanas, encontramos los siguientes datos mostrados en la figura 2. Un $64 \%$ de las imágenes en las que la(s) mujer(es) o/y hombre(s) no muestran relación alguna, un 27\% en las que la relación entre ambos sexos es recíproca y un 9\% en las que aparecen solo mujeres relacionándose.

FIGURA 2. Interacciones humanas

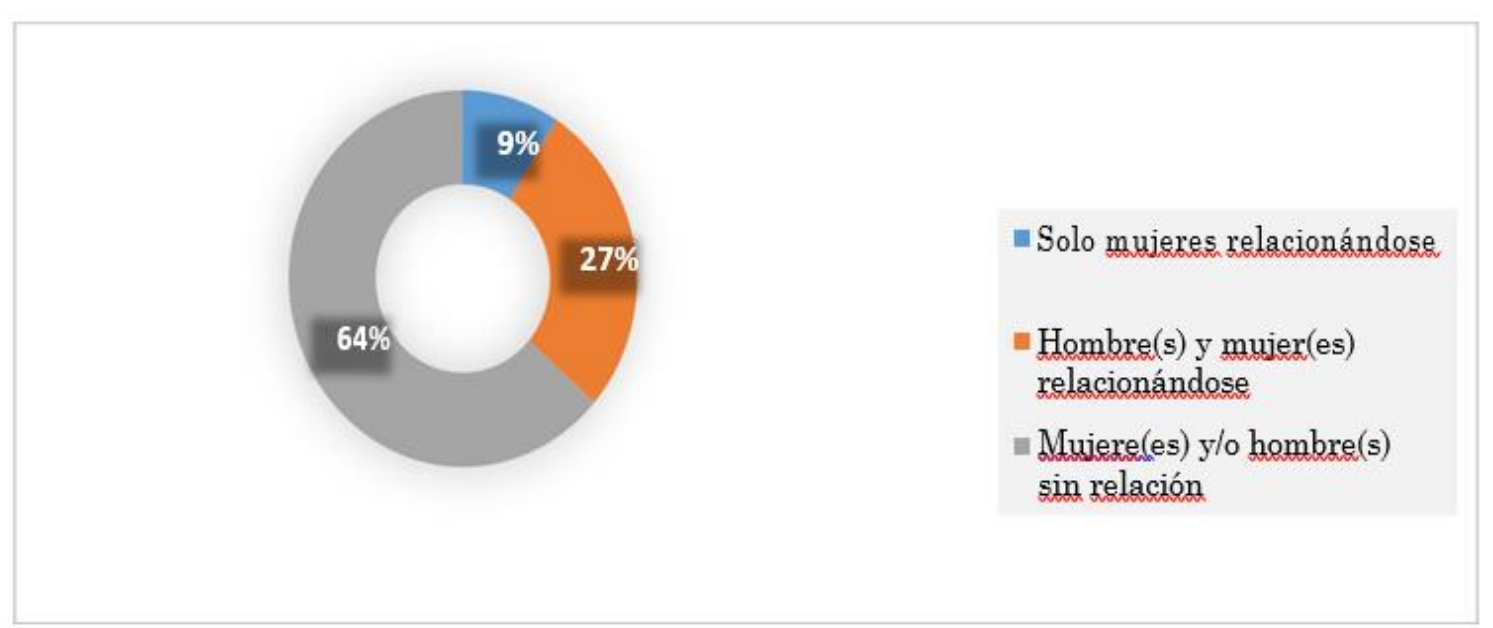

Fuente: Propia, 2017 
Ciencias Naturales $6^{\circ}$ curso de educación primaria. En las imágenes analizadas para este libro de texto, se puede detectar distintas emociones, como bien refleja la Figura 3 y la Figura 4. Se detecta que un $30 \%$ de las imágenes protagonizadas por hombres manifiestan alegría y un $42 \%$ de las imágenes en las que aparecen mujeres éstas exponen alegría. En un 8\% las mujeres expresan dulzura y esta misma emoción aparece en el hombre en un 10\%. En el 50\% restante de las imágenes en las que aparecen mujeres éstas transmiten otras emociones como satisfacción, asombro, duda, timidez y concentración. Los hombres aparecen representados en el restante $60 \%$ de las imágenes expresando las emociones centradas en asombro y esfuerzo.

FIGURA 3. Emociones centradas en la mujer

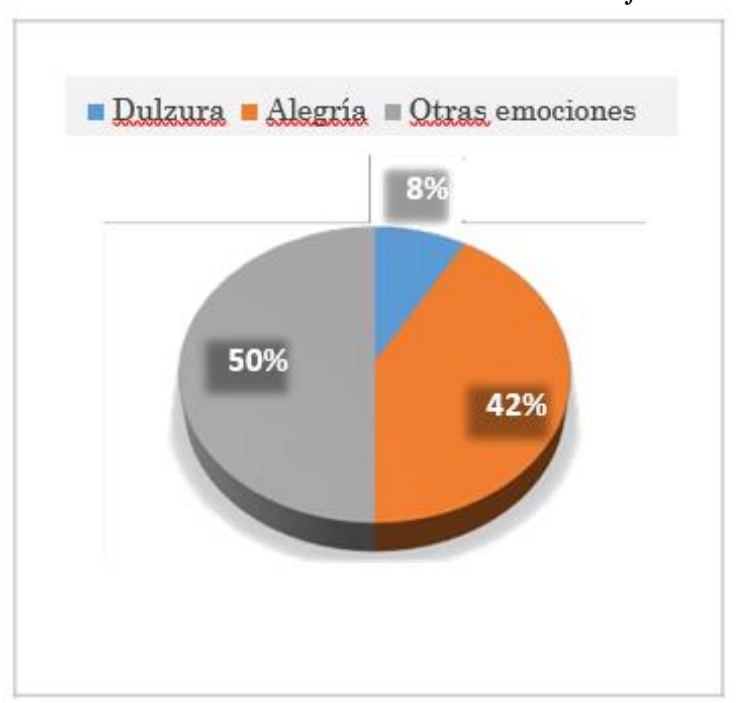

Fuente: Propia, 2017
FIGURA 4. Emociones centradas en el hombre

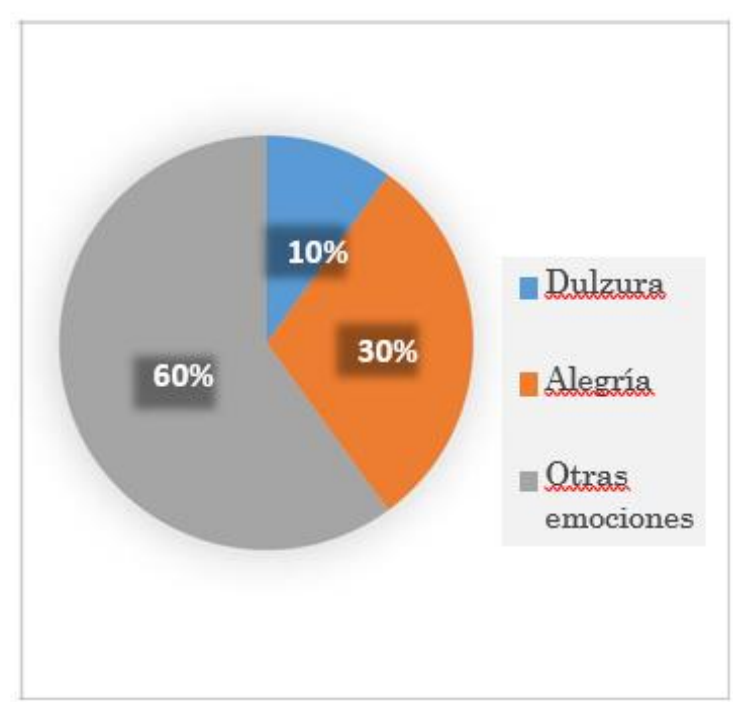

Fuente: Propia, 2017

En cuanto a las interacciones humanas, basándonos en los datos analizados y la Figura 5 destaca notablemente el $82 \%$ de las ocasiones en las que no existe relación entre ambos sexos, aunque si se da mutuamente en un $9 \%$ de imágenes donde aparecen mujeres relacionándose entre sí. Otro 9\% de imágenes donde existe relación entre hombres y mujeres. 
FIGURA 5. Interacciones humanas

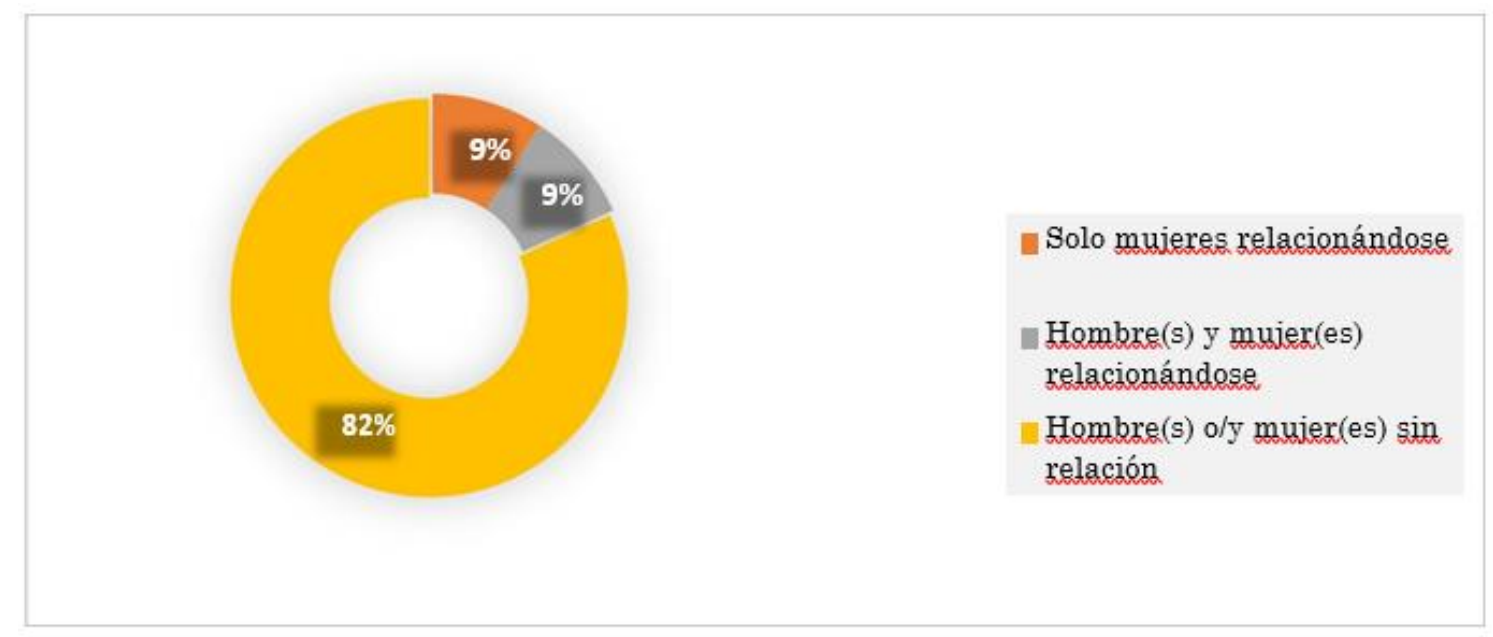

Fuente: Propia, 2017

Ciencias Sociales $2^{\circ}$ curso de educación primaria. Las emociones que se pueden detectar en ambos sexos ilustradas en la figura 6 y la figura 7 remiten a que la emoción de dulzura se representa en el 5\% de las imágenes donde aparecen los hombres y en el 9\% de las imágenes donde aparecen las mujeres. La emoción de alegría está presente en el $82 \%$ de las imágenes donde están presenten las mujeres y en el 79\% de las imágenes donde los hombres son protagonistas. Existe un 16\% de imágenes donde los hombres expresan otras emociones (orgullo y concentración) y un $9 \%$ de imágenes femeninas en las que estás expresan otras emociones relacionadas con el bienestar.

FIGURA 6. Emociones mostradas por hombres

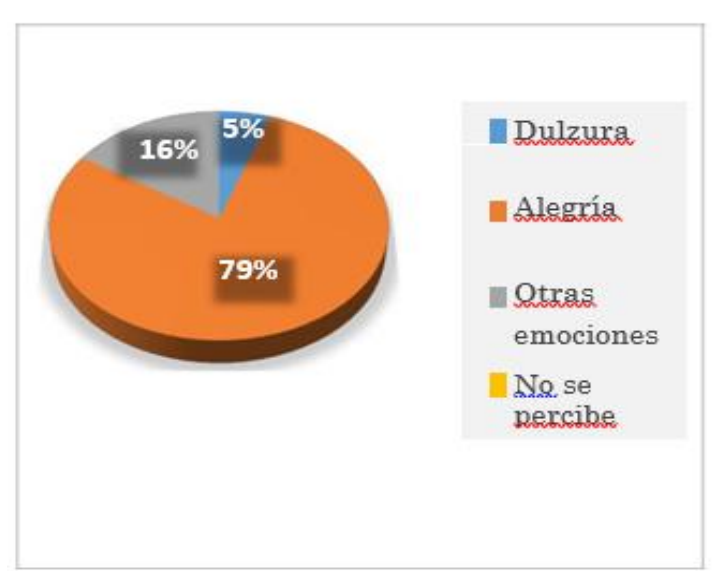

Fuente: Propia, 2017
FIGURA 7. Emociones mostradas por mujeres

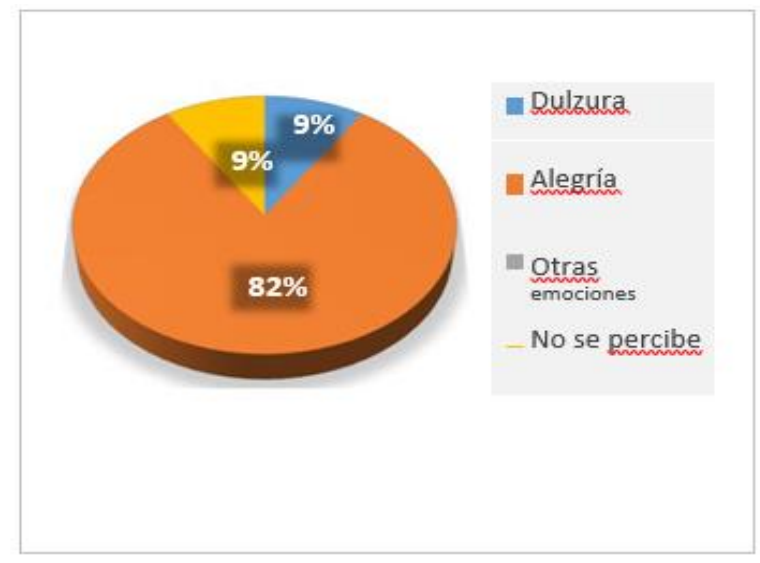

Fuente: Propia, 2017 
Esta dimensión también analiza las interacciones humanas recogidas en la Figura 8. En dicha categoría se advierte el predominio de hombres y mujeres relacionándose en un 49\% de los casos. También se observa un 36\% en que solo aparecen hombres relacionándose y un 15\% de imágenes en las que se aprecian hombres y mujeres sin llevar a cabo relación.

FIGURA 8. Interacciones humanas

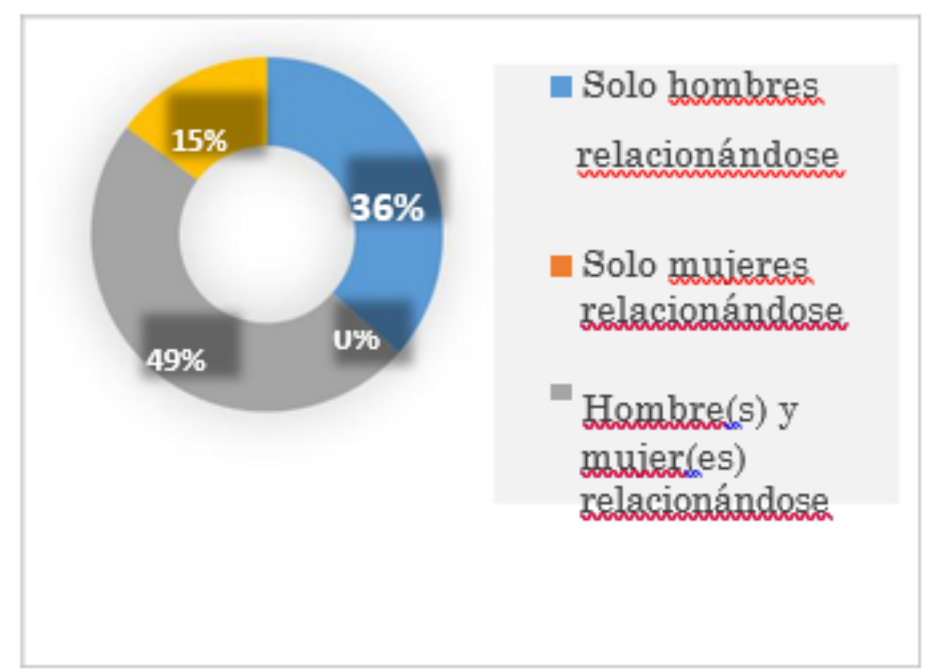

Fuente: Propia, 2017

En cuanto a las relaciones de cariño que se pueden extraer de estas imágenes, predominan en un 58\% de ocasiones sin relación de cariño, un $25 \%$ en las que un hombre muestra cariño hacia otro.

En el libro de Ciencias Sociales. $4^{\circ}$ curso de educación primaria, si atendemos a las emociones que trasmiten ambos sexos, los datos extraídos en la figura 9 y figura 10 nos apuntan lo siguiente: en el $17 \%$ de las imágenes protagonizadas por mujeres, éstas aparecen emitiendo dulzura; el $28 \%$ de las imágenes donde los hombres son protagonistas estos manifiestan alegría. La alegría es manifestada por mujeres en el 25\% de las imágenes analizadas; el 43\% aparecen otras emociones en hombres (concentración, sorpresa y preocupación) y 33\% aparecen otras emociones en mujeres (sorpresa, concentración y confusión); y un $25 \%$ sin percibir en mujeres y $29 \%$ en hombres. 
FIGURA 9. Transmisión emociones mujer

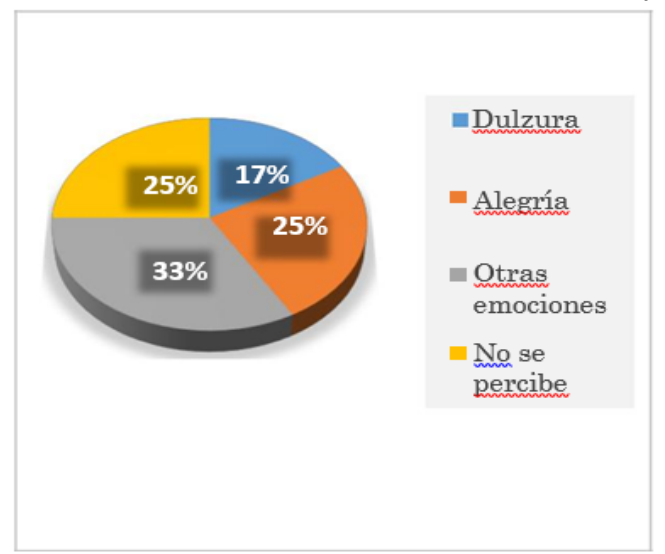

Fuente: Propia, 2017
FIGURA 10. Transmisión emociones hombres

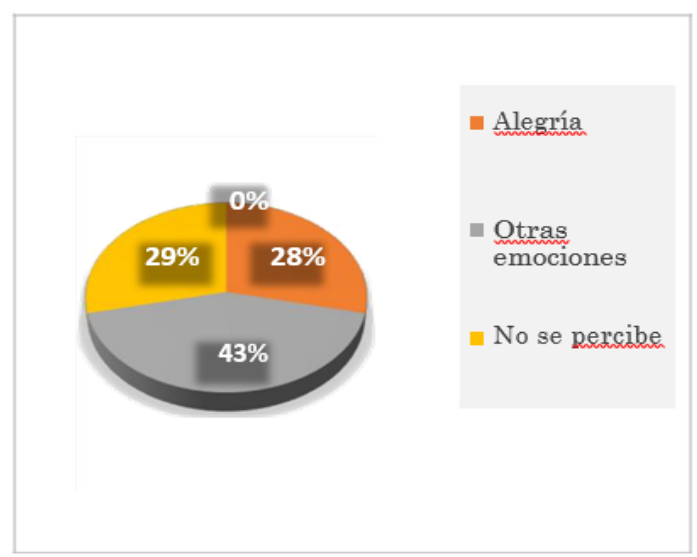

Fuente: Propia, 2017

Con respecto a las interacciones humanas, representadas en la Figura 11 en las imágenes se halla un 58 \% de mujer(es) y/o hombre(s) sin relación; un 17\% de ambos sexos relacionándose, un 17\% de hombres relacionándose entre ellos y un $8 \%$ de las imágenes donde aparecen solo mujeres sin relación. Por lo cual, lo más abundante es la falta de relación.

En lo que respecta a las actitudes de cariño, solo un $10 \%$ de las imágenes muestran cariño entre mujeres, el resto, 90\% de las imágenes los hombres y las mujeres no muestran ninguna relación de cariño.

FIGURA 11. Interacciones humanas

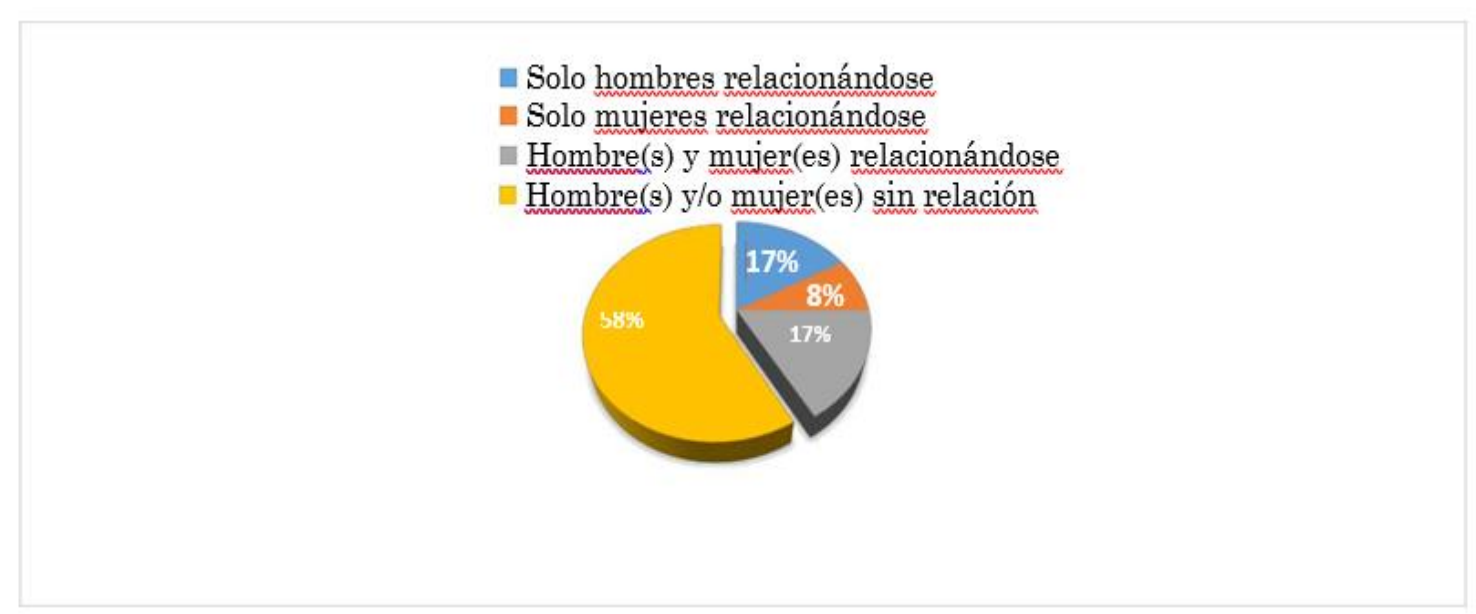

Fuente: Propia, 2017 
Ciencias Sociales $6^{\circ}$ curso de educación primaria. Los datos recogidos acerca de las emociones trasmitidas por las personas representadas en las imágenes se encuentran representadas en las figuras 13 y 14. En dichas figuras se muestran los siguientes porcentajes: $44 \%$ donde se muestran hombres alegres y $31 \%$ en mujeres, $6 \%$ donde las mujeres demuestran dulzura, el $25 \%$ de las imágenes no se perciben emociones en mujeres. Existe un 56\% de imágenes en las cuales los hombres aparecen manifestando de otras emociones (concentración, asombro, desconcierto y de disgusto) y un $38 \%$ de imágenes en las cuales las mujeres expresan curiosidad y serenidad. En este libro de texto, se aprecia un predominio de emociones de alegría mostradas por hombres así como una mayor variedad de emociones en ellos, aunque éstas son emociones negativas, que, contrariamente al hombre, la mujer no las trasmite.

FIGURA 13. Emociones representadas mujeres

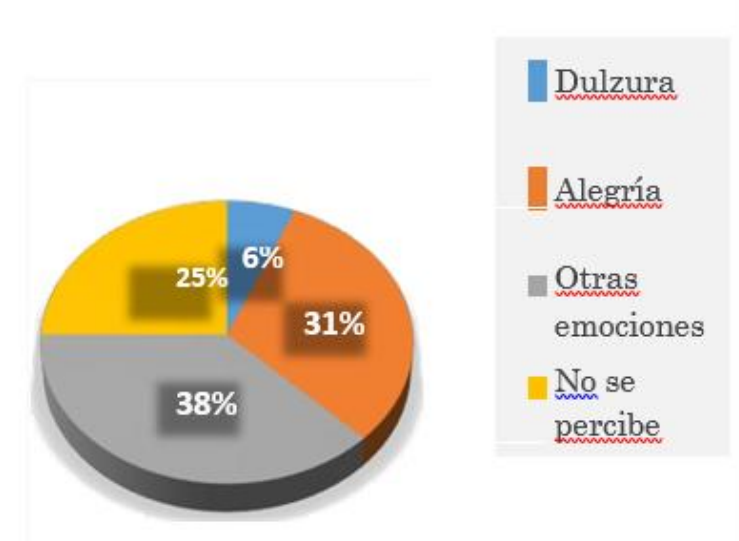

Fuente: Propia, 2017
FIGURA 14. Emociones representadas varones

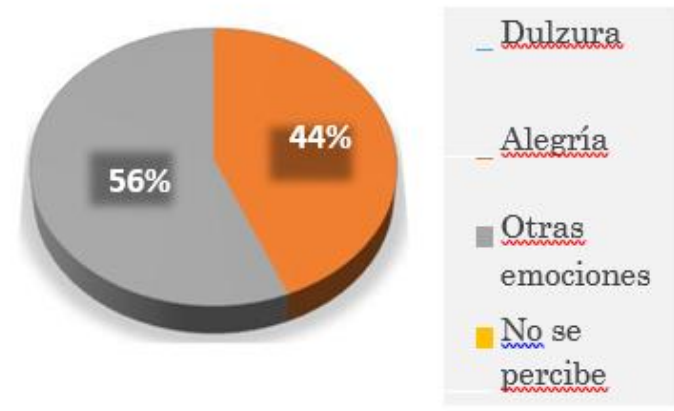

Fuente: Propia, 2017

En cuanto a las interacciones humanas manifestadas y expuestas en la Figura 15, encontramos un $11 \%$ de imágenes en las que aparecen mujeres relacionándose entre ellas; un 33\% de hombre(s) y/o mujer(es) sin relación y un $56 \%$ en las que ambos sexos se relacionan. A pesar de estar relacionándose en esas proporciones, las actitudes de cariño solo se dan em un $10 \%$ de hombre a hombre, otro $10 \%$ recíproca entre ambos sexos y el $80 \%$ restante de imágenes se detecta que la relación de cariño no existe. 
FIGURA 15. Interacciones humanas

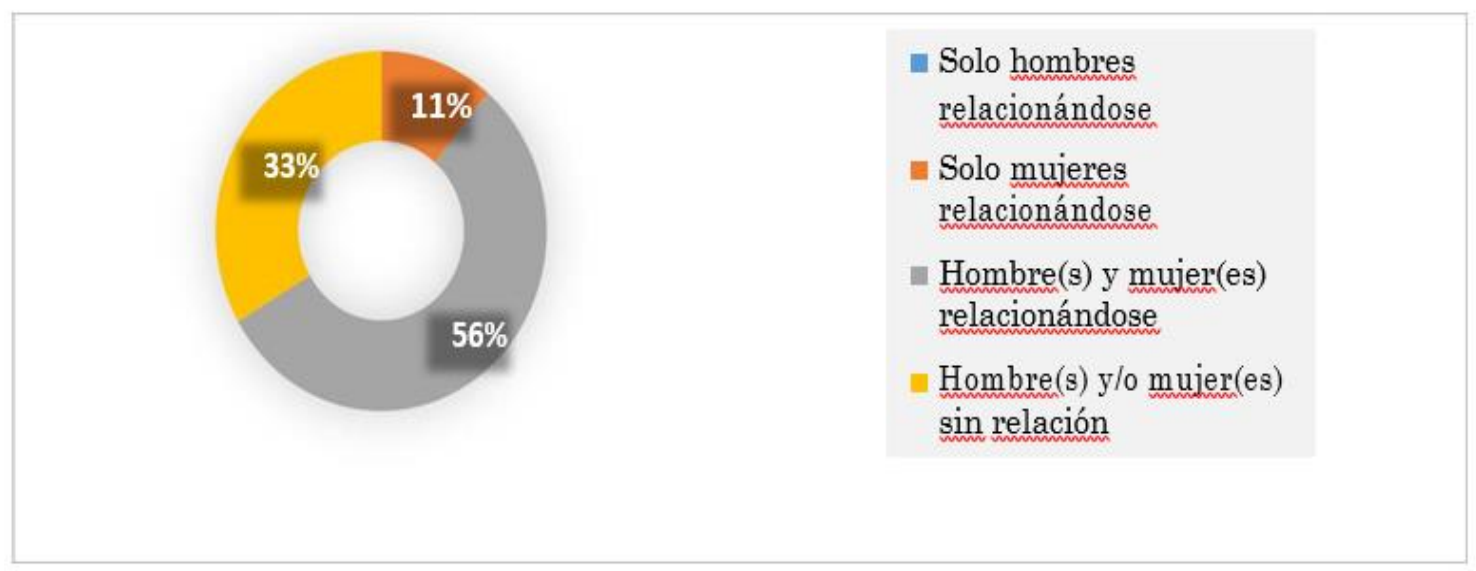

Fuente: Propia, 2017

Antes de concluir este apartado sobre el análisis de imágenes en los seis libros de texto, hay que resaltar que no se ha detectado ninguna expresión relacionada con emociones vinculadas a expresiones de rechazo, abuso / violencia sexual o fobias sexuales. Tampoco ninguna imagen en la que de forma explícita se pueda advertir indicadores que se incluyan en la definición de sexualidad promocionada por la OMS (2006).

\section{Conclusiones}

En los libros de texto analizados de Ciencias Sociales y Ciencias Naturales de la etapa de primaria, se destaca que son los modelos femeninos quienes representan en muchas más ocasiones emociones que los modelos masculinos. Las emociones femeninas que más sobresalen, son la dulzura y la alegría. Los hombres son portadores de emociones ligadas a la toma de decisión, a la concentración, la preocupación, el asombro, el orgullo o el miedo, entre otras. A las mujeres se las sigue ligando a emociones vinculadas con los afectos, la felicidad y las actitudes de bienestar. Aunque la tendencia esté cambiando y las mujeres están más representadas en los libros de texto, hay que señalar que siguen apareciendo bajo estereotipos sexistas que las muestran vinculadas a cualidades centradas en el ámbito 
emocional personal pasivo. Mientras que los varones aparecen exponiendo emociones más activas proyectadas al desarrollo profesional. Esta conclusión se relaciona con otros estudios en los que se advierten cómo se proyectan los modelos femeninos respecto a los masculinos en los textos escolares de las diversas áreas de conocimiento y que coinciden en afirmar que aún se difunde una visión segregadora respecto a las expresiones y actitudes personales que se enseñan asociando a las mujeres con los valores estéticos y expresivos (TÁBOAS \& REY, 2007; 2011; BLANCO, 2008).

En los seis los libros de texto supervisados aparecen las interacciones reciprocas entre ambos sexos con alto porcentaje de representatividad tanto en los textos de Ciencias Naturales como de Ciencias Sociales. Esta situación se advierte de forma más clara en los libros de texto de Ciencias Sociales, donde predominan contenidos curriculares prescriptivos más en consonancia con las relaciones personales y el aprendizaje en grupo. Sin embargo, los porcentajes de imágenes donde no hay relación entre sexos, en forma de interacciones están más presentes tanto en Ciencias Sociales como en Ciencias Naturales. Esto entra en contradicción con lo que ambas áreas deberían potenciar sobre la competencia social y ciudadana recogida junto a otras seis más en la actual Ley Educativa LOMCE (2013). Dicha competencia tiene entre otros los siguientes contenidos.

(...) Las destrezas de esta competencia están relacionadas con la habilidad para interactuar eficazmente en el ámbito público y para manifestar solidaridad e interés por resolver los problemas que afecten al entorno escolar y a la comunidad (...), (...) La participación constructiva incluye también las actividades cívicas y el apoyo a la diversidad y la cohesión sociales y al desarrollo sostenible, así como la voluntad de respetar los valores y la intimidad de los demás (LOMCE, 2013).

Asimismo, las muestras de relación entre personajes del mismo sexo se encuentran en cantidades muy bajas e incluso, en muchas ocasiones, son 
inexistentes en uno y otro sexo en ambas áreas de conocimiento. Lo recomendable sería potenciar las relaciones de reciprocidad, pero sin anular las interacciones entre sexos iguales. $\mathrm{Y}$ representar las interacciones intersexuales sin exclusiones. Existe muy poca representatividad sobre las relaciones de un mismo sexo en los textos escolares lo que sigue potenciado una idea del binarismo en la escuela que representa de manera poco real las relaciones sociales y que aumenta la posibilidad de seguir generando conocimientos desde el paradigma heteropatriarcal.

En estos libros de texto ni se visibilizan las interacciones reciprocas entre hombres y mujeres y tampoco se exponen imágenes donde se vean interacciones protagonizadas por personas del mismo sexo. Estas imágenes expresan fórmulas de relación planas y poco reales en cuanto a lo que se lleva a cabo en la realidad social. Esta expresión de conocimientos relacionada a como se proyectan las relaciones repercutirá bastante en el aprendizaje sobre la socialización en edades de desarrollo temprano. Ya que es en estas edades cuando comienzan a generarse los grupos sociales relacionales y se podría promocionar un conocimiento que remarcarse la segregación sexual. Por ello, se debe potenciar desde los libros de texto imágenes equilibradas en términos de porcentajes en las que se visualizaran relaciones entre distintos sexos y también del mismo sexo para romper las posibles relaciones lineales de mismo sexo. Con todo, podemos concluir como Torres (2011) afirmando la existencia, en los libros de texto, de una serie de distorsiones informativas reconocibles de manera simple que dan lugar a diferentes estrategias educativas incorrectas: segregación, exclusión, desconexión, tergiversación, psicologización, paternalismo-pseudotolerancia, infantilización, como realidad ajena o extraña.

Como aspecto negativo, se advierte que en ninguna imagen analizada hay una clave en las que se represente la sexualidad según el modelo trabajado desde la OMS (2006) lo que viene a reafirmar que contamos con una realidad preocupante en el sistema educativo español: las escasas prácticas existentes asociadas al tema de la educación en sexualidad en las 
aulas y los libros de texto en primaria (PELLEJERO \& TORRES, 2011). Esto es debido a que el currículo identifica sexualidad con el área disciplinar de la Biología. Resaltamos lo que mantiene López (2005) que afirma que la educación sexual en la escuela ha sido un fracaso. Considera que, entre otros motivos, se debe a que los responsables del Ministerio de Educación temen plantear con claridad y decisión estos temas. Se suma un argumento más y es la falta de preparación que tienen los maestros y maestras de nuevas generaciones, en las cuestiones relacionadas con la igualdad y la sexualidad (AGUILAR, 2015) y por tanto se recoge la necesidad de orientar al profesorado de la formación inicial de maestro/a, en nuevos modelos de relación afectivo- sexual alejados de la violencia, que ha demostrado la transformación de la desigualdad (VALLS \& PUIGVERT, 2008).

Por último, como aspecto positivo, que se quiere destacar es que en el $100 \%$ de las imágenes analizadas no existen rasgos sobre relaciones que muestren de abusos y / o fobias sexuales. Sin embargo, sería oportuno incrementar las imágenes donde se expongan relaciones de cariño entre sexos para trasmitir mensajes donde de respeto y se expongan muestras de relaciones en base a la diversidad afectiva sexual. Estas relaciones de cariño les servirían como ejemplo para enseñar comportamientos pedagógicos basados en la igualdad social.

\section{Referencias}

AGUILAR, C. Igualdad, género y diversidad sexual en la Formación Inicial de Maestro/a en la Universidad Jaume I (UJI). Temas de educación, v. 21, n. 1, p.7796.

BEJARANO, M. y MATEOS, A. Género y sexualidad en la formación inicial de maestros y maestras. ¿Por qué no un currículum sexual? Exedra (Suplemento de diciembre: Sexualidade, género e educação), p. 127-146. 2014.

Reflexiones y propuestas para mejorar la educación afectivosexual en España. En RIBEIRO, P., SILVA, E. y TEIXEIRA, F. (Eds.) Atravessamentos de genero, corpos e sexualidades: Linguagens, Apelos, desejos, posibilidades e desafíos. Rio Grande: Universidad Federal Do Rio Grande-FURG. 2016. 
BLANCO GARCÍA, N. Análisis de materiales curriculares. En Vega Navarro, A. (Coord.) (2007), Mujer y educación. Una perspectiva de género. Málaga: Ediciones Aljibe. 2007.

. Los saberes de las mujeres y la transmisión cultural en los materiales curriculares. Revista Investigación en la Escuela, n. 65, p. 11-22, 2008.

BISQUERRA, R. (Coord.). Metodología de la investigación educativa. Madrid: La Muralla. 2014.

CARRERAS, A.; SUBIRATS, M. y TOMÉ, A. La construcción de las identidades de género en la etapa de 0-3. Primeras exploraciones. En GARCÍA MARÍN, J. y. Gómez Vázquez, M.B. (Eds.) Diálogos en la cultura de la paridad. Reflexiones sobre feminismo, socialización y poder. Santiago de Compostela: USC Publicacións. 2012.

DIZ, M. J. y FERNÁNDEZ RIAL, R. Criterios para el análisis y elaboración de materiales didácticos coeducativos para la educación infantil. Reladei, v. 4, n.1, p. 105-124. 2015.

DÍAZ-BARRIGA ARCEO, F. Los profesores ante las innovaciones curriculares. Revista Iberoamericana de Educación Superior (RIES), v.1, n. 1, p. 37-57. 2010

HERNÁNDEZ SAMPIERI, S., FERNÁNDEZ COLLADO, C. y BAPTISTA LUCIO, P. Metodología de la investigación. $6^{\text {a }}$ Ed. México: McGrawHill. 2014.

HSIEH, H. y SHANNON, S. Three approaches to qualitative content analysis. Qualitative health research, v.15, n. 9, p. 1277-1288. 2005.

Ley Orgánica 8/2013, de 9 de diciembre, para la mejora de la calidad educativa.

LOMAS, C. El sexismo en los libros de texto. En GONZÁLEZ, A. y LOMAS, C. (Coords.), Mujer y educación: educar para la igualdad, educar desde la diferencia. $3^{\mathrm{a}}$ Ed. Barcelona: Graó. 2003.

LÓPEZ, F. La educación sexual. Madrid: Biblioteca Nueva, 2005.

MARTÍNEZ BONAFÉ, J. y RODRÍGUEZ RODRÍGUEZ J. (2010). El currículum y el libro de texto escolar. Una dialéctica siempre abierta. En GIMENO SACRISTÁN, J. (comp.), Saberes e incertidumbres sobre el currículum (pp. 246-268). Madrid: Morata.

MORGADE, G., BAEZ, J., ZATTARA, S. Y DÍAZ VILLLA, G. Pedagogías, teorías de género y tradiciones en 'educación sexual'. En Morgade, G. (Coord.), Toda educación es sexual: hacia una educación sexuada justa. Buenos Aires: La Crujía. 2011.

PELLEJERO, L .y TORRES, B. La educación de la sexualidad: el sexo y el género en los libros de educación primaria. Revista de Educación, n.354, p. 399-427, abril, 2011. 
PÉREZ LÓPEZ, A. El sexismo en los manuales escolares de ciencias sociales de la E.S.O. (T.F.M, Universidad de Salamanca). Recuperadode:

http://repositorio.ual.es/jspui/handle/10835/1142\#.UTIgBTcdX6s. $\quad$ Consulta: $5 / 02 / 2018$.

ONUSIDA (2011). Lograr la salud y los derechos sexuales y reproductivos para las mujeres y las niñas a través de la respuesta al VIH. Recuperado en: http://www.unaids.org/es/resources/presscentre/featurestories/2011/july/20110719w omenias. Consulta: 29/01/2018.

Organización Mundial de la Salud (2006). Defining sexual health: report of a technical consultation on sexual health. Recuperado de http://www.who.int/reproductivehealth/publications/sexua_health/defining_sexual_ healt h.pdf. Consulta: 28/01/2018.

Organización de las Naciones Unidas para la Educación la Ciencia y la Cultura (UNESCO). (2010). Orientaciones técnicas internacionales sobre educación en sexualidad. Un enfoque basado en evidencia orientado a escuelas, docentes y educadores de la salud. Santiago: Autor. Recuperada de http://unesdoc.unesco.org/images/0018/001832/183281s.pdf

Organización de las Naciones Unidas para la Educación la Ciencia y la Cultura.

UNESCO (2014). Educación Integral de la sexualidad, conceptos enfoques y competencias. Oficina Regional de Educación para América Latina y el Caribe.

RAWLS, J. La justicia como equidad. Una reformulación. Barcelona: Paidós, 2002.

TÁBOAS, M. I., \& REY, A. El cuerpo en las imágenes de los libros de texto de educación física: análisis de dos editoriales. Kronos, n. 11, p. 10-15. 2007.

. Las imágenes en los libros de texto de Educación Física de la ESO: modelos corporales y actividad física. Revista de Educación, n. 354, p. 293-322. 2011.

TERRÓN, M. T., Y COBANO, V. (2009). El papel otorgado a la mujer en los textos escolares de educación primaria en Marruecos y España. Estudio comparado. Educatio Siglo XXI, v. 27, n. 1, p. 231 -248.

TORRES, J. La justicia curricular. El caballo de Troya de la cultura escolar. Madrid: Morata. 2011.

VALLS, R. y PUIGVERT, L. Gender Violence Among Teenagers. Socialization and Prevention. Violence Against Women, v.7, n.14, p. 759-785, 2008. 